\title{
The Centenary of the Discovery of Insulin: An Update on the Quest for Oral Delivery
}

\author{
David J. Brayden* \\ University College Dublin (UCD) School of Veterinary Medicine, UCD Conway Institute of Biotechnology; and the Science \\ Foundation Research Centre for Medical Devices (CURAM), Dublin, Ireland
}

Not many topics in drug delivery science have exercised so many pharmaceutical, formulation, and bioengineering minds than the oral delivery of macromolecules, especially when insulin is the focus. The year 2021 marks a hundred years since the discovery of insulin by Banting and Best to treat Type 1 diabetes. Repeated efforts to deliver it orally since then have met with failure, with particular disappointment resulting from encouraging preclinical studies in the 1980s. Here, the barriers to synthesizing successful oral inulin formulations are discussed. It is apparent that this peptide has chemistry and pharmacology features that make its oral delivery one of the toughest challenges in delivery science. At this seminal point in its history, the question is whether oral delivery of insulin will ever be possible, or even if this quest is still desirable?

\section{OPEN ACCESS}

Edited by:

Susan Hua,

The University of Newcastle, Australia

Reviewed by:

Mariko Takeda-Morishita, Kobe Gakuin University, Japan Anette Mullertz,

University of Copenhagen, Denmark

*Correspondence:

David J. Brayden david.brayden@ucd.ie

Specialty section: This article was submitted to Oral Drug Delivery, a section of the journal

Frontiers in Drug Delivery

Received: 17 June 2021 Accepted: 03 September 2021 Published: 15 September 2021

Citation:

Brayden DJ (2021) The Centenary of the Discovery of Insulin: An Update on

the Quest for Oral Delivery.

Front. Drug. Deliv. 1:726675.

doi: $10.3389 /$ fddev.2021.726675
Keywords: oral peptide delivery, insulin, non-injected drug delivery, macromolecules, diabetes, hyperglycaemia, hypoglycaemia

\section{INTRODUCTION}

Shortly after insulin was discovered (reviewed in Vecchio et al., 2018), one of the very first studies indicated that insulin could not be delivered by the oral route using dilute alcohol as a solvent (Harrison, 1923). Despite what was a pilot study, serious attempts did not follow for decades as the received wisdom was that macromolecule delivery by the oral route was not possible. To this day, basal- and short-acting insulins are administered either by subcutaneous (SC) injections for both Type 1 and 2 diabetics, or by implantable pumps for Type 1 diabetics. A significant (and somewhat overlooked) recent technical achievement for pain-free administration has allowed short-acting insulin to be delivered across the pulmonary epithelium for meal-time administration in inhaled formulations (Afrezza ${ }^{\circledR}$ Mannkind, NJ, United States; Exubera ${ }^{\circledR}$ (Pfizer, CT, United States), (AlTabakha, 2015). Initial fears over the potential toxicity of inhaled insulin have been allayed to some extent (McGill et al., 2020). Yet patient take-up for Afrezza remains elusive due to cost and reimbursement issues, a reluctance of endocrinologists to switch their patients from injections, and the lack of competition in insulin pricing in the United States (Knox, 2020). These important nonscience factors must also be considered if an orally delivered insulin ever proves to be technically possible.

\section{Insulin Selection for Oral Macromolecular Delivery}

Successful oral delivery of peptides is hampered by instability in the intestinal tract, attack from intestinal peptidases, and inherent low epithelial permeability due to large molecular weight and hydophilicity (Drucker, 2020). Nominating insulin as a payload for oral peptide delivery technologies has its pros and cons. Insulin can be viewed as an attractive selection because the main target is the 


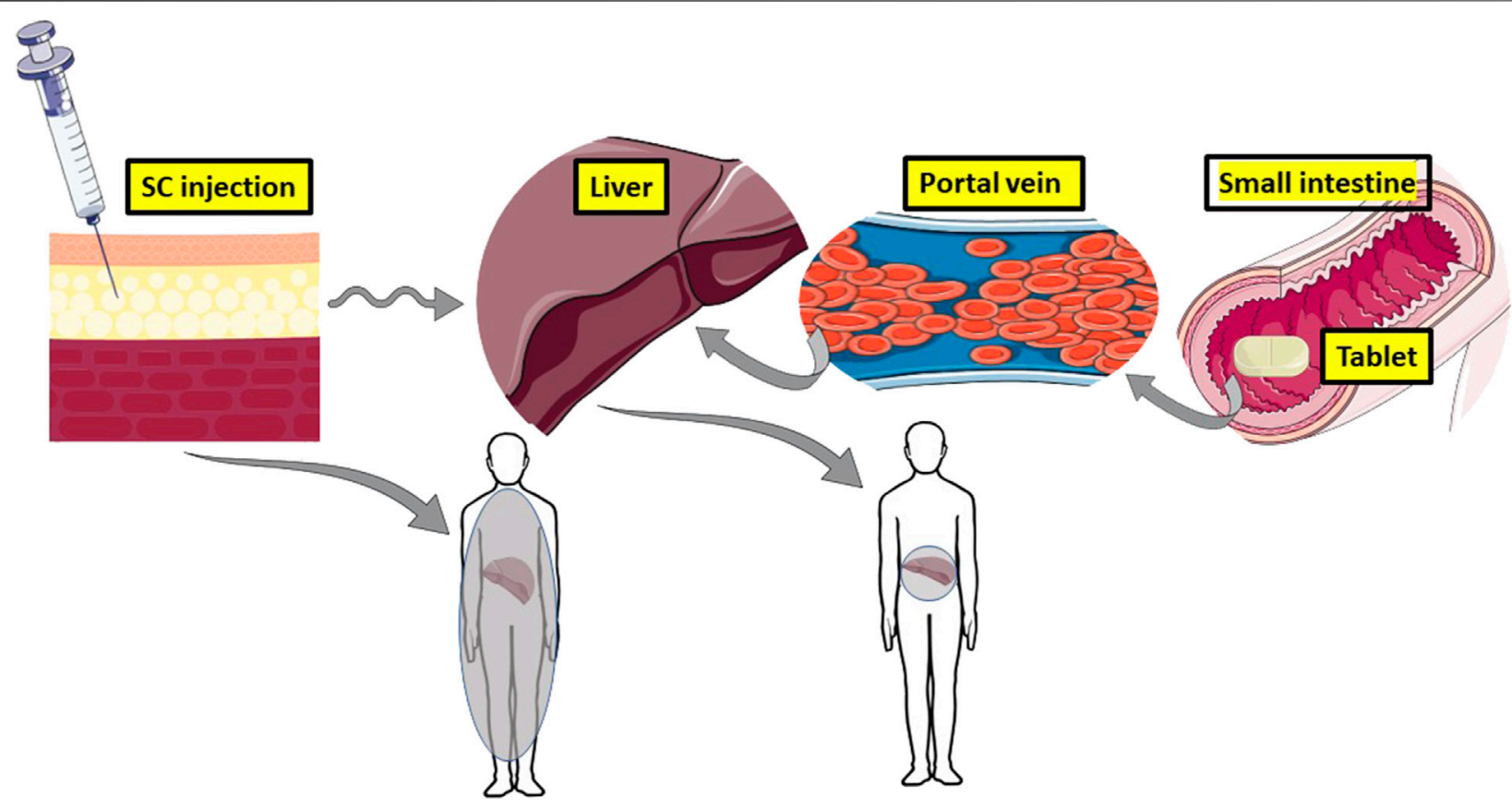

FIGURE 1 | The theoretic advantage of oral insulin versus subcutaneous (SC) injection. An oral dosage form of insulin mimics physiological secretion from pancreatic beta cells to the hepatic portal vein, which serves the liver. 50\% of insulin is inactivated at the liver target, so little of it reaches the periphery and it concentrates in the liver (grey). SC administration of insulin floods the periphery to cause hypoglycaemia and hyperlipidaemia. Only $10 \%$ of it reaches the liver, hence the lack of targeting (diffuse grey in the body). Images adapted from Servier Medical Art by Servier is licensed under a Creative Commons Attribution 3.0 Unported License.

liver, and it is also reached physiologically when insulin is released by the pancreas to the hepatic portal vein (Zijlstra et al., 2014) (Figure 1). The oral route, therefore, mimics the endogenous pathway to the liver. Insulin is also an excellent model peptide to benchmark a delivery technology as there are ample published datasets in animal models to compare against. Given its challenges, if an oral formulation or device technology can deliver insulin to an acceptable level, then surely it has potential for other peptides of similar molecular weight and potency? Another advantage is the availability of ELISAs for human insulin in plasma and simple assays to measure blood glucose across several species, so its selection allows researchers that lack the major analytic laboratory capacity of large Pharma to participate in oral peptide delivery research.

\section{The Arguments for Oral Insulin for Diabetic Patients}

There are some strong arguments in favour of the benefits of orally administered insulin compared to injections. The numbers of Type II diabetic patients adhering to the SC chronic dosing regimen for insulin is low, estimated as less than 50\% (Sharma et al., 2020). Many Type II diabetic patients delay by more than 2 years going onto insulin from when first offered it, while others may adhere to the dosing regimen at the beginning, but then their commitment may wane. For S.C.administered insulin, despite the improvements in needle- and insulin pen technology, there are still injection site reactions
(Gentile et al., 2016), while up to $10 \%$ of Type 2 diabetic patients have a fear of needles (Rubin et al., 2009). Administration of insulin by the S.C. route floods the periphery with insulin causing hyperinsulinemia, along with the common side-effect of hypoglycaemia (Figure 1) (McCall, 2012). Risk of hypoglycaemia from injections is one of the reasons why pre-Type II diabetic patients are not prescribed insulin earlier in their disease, even though it may delay disease progression. That problem can be addressed in part by substituting insulin for glucagon-like peptide-1 receptor agonists (GLP-1-RA), which stimulate insulin secretion when blood sugar is elevated. Patient preference for the oral route for peptides is apparent from studies demonstrating their support for twice-a-day oral octreotide capsules compared to once monthly intramuscular injections with low gauge needles (Melmed et al., 2015), and for a once-a-day tablets of GLP1-RA, Rybelsus ${ }^{\circledR}$ (semaglutide, Novo Nordisk, Bagsværd, Denmark) compared to injectable GLP1-RA options (Igarashi et al., 2021). There is therefore little doubt that diabetic patients would also prefer an oral option for insulin.

\section{The Counter-Arguments for Oral Insulin for Diabetic Patients}

Insulin may be considered a weak candidate for oral delivery because it has a low therapeutic index (Lamont et al., 2010) and because there will be very large variation in oral bioavailability from 
TABLE 1 | Ten key papers in oral insulin delivery research (selected).

\begin{tabular}{|c|c|c|}
\hline References & Findings & Relevance \\
\hline $\begin{array}{l}\text { Dapergolas and } \\
\text { Gregoriadis (1976) }\end{array}$ & $\begin{array}{l}\text { Intragastric administration of insulin in a liposome based on } \\
\text { dipalmitoylphosphatidylcholine and cholesterol reduced blood glucose in } \\
\text { normal and diabetic rats }\end{array}$ & $\begin{array}{l}\text { One of the first attempts to use a particle-based system in the Gl } \\
\text { tract to deliver insulin. Liposomes did not pan out as a platform due } \\
\text { to instability and low loading }\end{array}$ \\
\hline Damgé et al. (1988) & $\begin{array}{l}\text { Polyalkylcyanoacrylate nanocapsules entrapped with insulin lowered blood } \\
\text { glucose in normal and diabetic rats following gavage }\end{array}$ & $\begin{array}{l}\text { Possibly the first insulin nanoparticle paper. Issues were the high } \\
\text { insulin dose, lack of PK, and the formulation did not translate to the } \\
\text { dog model }\end{array}$ \\
\hline Saffran et al. (1991) & $\begin{array}{l}\text { A bacteria-sensitive azo-polymer in gelatin capsules with a permeation } \\
\text { enhancer released insulin in the colon for systemic delivery in diabetic dogs }\end{array}$ & $\begin{array}{l}\text { Although insulin was delivered, it was not dose-related and required } \\
\text { repeated dosing to reduce blood glucose. Because it took up to } 2 \mathrm{~h} \\
\text { to reduce blood glucose, the study highlighted some of the } \\
\text { disadvantages of colonic delivery for insulin. The concept is still } \\
\text { being used as a local topical approach to treat ulcerative colitis with } \\
\text { other molecules }\end{array}$ \\
\hline
\end{tabular}

Mathiowitz et al. (1997) Polyanhydride co-polymers of fumaric and sebacic acid, poly (FA:SA) entrapped insulin in microparticles and showed efficacy in rat glucose challenge model following oral administration

This study promoted the concept of bioadhesion to the epithelium followed by microparticle particle uptake by Peyer's patches and enterocytes. The design did not move to clinical trials, but it stimulated interest in biocompatible microparticle research

Morishita et al. (2004) Hydrogels of PEG were grafted onto polymethacrylic acid, P(MAA-g-EG), by the Peppas lab to make microparticles that released insulin in the small intestine upon $\mathrm{pH}$-dependent swelling

P(MAA-g-EG) microparticles generated bioavailabilities of $12 \%$ in rat loop gut instillation model. While the design did not move to clinical trials, it stimulated synthesis of hydrogels particulates by others

Pridgen et al. (2013) FCRn-targeted nanoparticles were made from PLA-PEG block copolymers and decorated with Fc. Evidence of translocation across the Gl tract in rodents with efficacy against a glucose challenge

Brought transporter targeting back to the nanoparticle discussion after the failure of the vitamin- $B_{12}$ coating approach. Lack of subsequent translation highlights issues around scale-up and reproducibility of targeted concepts

Eldor et al. (2013)

A pilot study from Oramed Pharma tested an capsule of $8 \mathrm{mg}$ insulin to replace mealtime injections three times a day in patients with Type 1

Blood glucose monitoring indicated a $16 \%$ reduction in glycaemia from this permeation enhancer and peptidase inhibition-based system. No larger trial resulted, however, and the focus of efforts by others shifted to delivering long-acting basal insulin

Banerjee et al. (2018) An oral insulin formulation using choline and geranate ionic liquid as a permeation enhancer reduced blood glucose in rats from a mini capsule with Dramatic reductions in blood glucose in rats corresponded to $51 \%$ a low dose of insulin

oral bioavailability, much higher than in previous papers

Abramson et al. (2019a) A SOMA device delivered insulin via a millipost-actuated solid-dose system in pigs when injected into Gl regions

$0.3 \mathrm{mg}$ insulin in the device yielded comparable data in pigs to SC injections. A step change improvement in insulin bioavailability over enhancers and nanoparticles. Brought device-based concepts into main-stream, but toxicology and scale-up may be barriers

Halberg et al. (2019) Modified basal insulin achieved 1-2\% oral bioavailability in phase II trial in patients with Type II diabetes

Enteric-coated tablet of 10338 with $\mathrm{C}_{10}$ gave best clinical trial data yet published on insulin. Set a benchmark for future trials

${ }^{a} F_{C} R n$ : neonatal FC receptor for IgG; PLA-PEG: poly (lactic acid)-b-poly (ethylene glycol); SOMA: self-orienting millimetre-scale applicator.

oral formulations achieving values of $<10 \%$. Despite improvements in monitoring glucose, excursions could offset any wider therapeutic benefits if the oral insulin dosage form failed to deliver enough insulin to the blood from the oral route on every occasion, which is almost certain with low mean bioavailability values. The risk of hypoglycaemia occurring from an unreliable oral formulation is also a real risk if the formulation delivered insulin excessively on occasion. Toxicological considerations also relate to potential issues around administering high doses of insulin (a growth promoter) to the GI tract where activation of insulin receptors could trigger undesirable cell proliferation, as described in rodents (Saffran et al., 1997). Even if a successful prandial insulin formulation was created, patients would still require availability of injectable insulin, as is the case with the inhaled prandial insulin (Afrezza ${ }^{\circledR}$ ).

\section{Skeptiscism Over whether Oral Insulin is Achievable}

Grant applications proposing insulin even as a model peptide to test an oral delivery technology inevitably attract the wrath of some reviewers. Many are sceptical of the capacity of an oral insulin programme to be achieved because there have been over 40 years of research that has over-promised and under-delivered. Also, the majority of oral insulin papers using rodents provide no pharmacokinetic data and many authors tend to exaggerate their 
technology's impact if blood glucose is reduced in the (overlysensitive) streptozocin diabetic rat model. Very few examples from technologies assessed in rodent studies have translated to formulations for large animal testing. The scepticism is compounded by the lack of reasons offered for failure across oral insulin clinical trials, of which only about thirty have been published on PubMed. It seems that there is little middle ground when it comes to discussing the rationale for oral delivery of insulin. An objective view is that there should be clear benefits of convenience and early adoption for oral insulin formulations by patients with diabetes, but there are hurdles to translation. These include low and variable efficacy of current formulations in Development, a dearth of studies in large animal models, potential toxicology of insulin in the GI tract, as well as its inherent low therapeutic index. Table $\mathbf{1}$ is a (non-scientific) selection of ten key oral insulin delivery papers from the literature that cover some of these issues.

\section{Clinical Development of Oral Peptide Formulations}

Much credit is due for the recent FDA approvals of oral semaglutide in 2019 (Rybelsus ${ }^{\circledR}$, Novo Nordisk, Bagsværd, Denmark) (Anderson et al., 2020) and of oral octreotide in 2020 (Mycappsa ${ }^{\circledR}$ Chiasma Pharma, Needham, MA, United States) (Samson et al., 2020). These formulations of highly potent peptides with a degree of intestinal stability are both based on intestinal permeation enhancers (Brayden et al., 2020), Rybelsus ${ }^{\circledR}$ with salcaprozate sodium (SNAC) (Buckley et al., 2018), and Mycappsa with sodium caprylate in an oily suspension (Brayden and Maher, 2021). While they achieved the required respective changes in plasma biomarkers for Type 2 diabetes and acromegaly, typical oral bioavailability values in humans for both peptides averaged $<1 \%$, and with large coefficients of variation. Such approaches unfortunately only apply to niche peptide candidates with exceptional potency, stability, and ideally with a long half-life to address intra-subject variability. Novo Nordisk researchers also published a Phase II trial of a long-acting basal insulin (IO338) formulated with the medium-chain fatty acid permeation enhancer, sodium caprate $\left(\mathrm{C}_{10}\right)$ (Halberg et al., 2019). Although the oral bioavailability of IO338 was estimated at 1-2\%, higher than that achieved in the two successful New Drug Applications above, the programme was discontinued because the cost of the insulin was regarded as too expensive. The large variability in bioavailability may also have been a factor from a toxicological point of view. It took $\sim 60$ times the dose of oral insulin to equate to the responses seen with the s. c. administered insulin control, so even though it was efficacious, it proved impractical to commercialise. At that time, Novo Nordisk was also focussed on the oral semaglutide programme with SNAC, so they opted for it and terminated the oral insulin programme with $\mathrm{C}_{10}$. Still, an accompanying Editorial described the Halberg study with IO338 as landmark achievement for oral insulin delivery research and went so far as to suggest that the textbooks would have to be revised
(Mathieu, 2019). Despite the low bioavailability achieved, the Halberg study is the most important clinical trial ever published on an oral insulin formulation.

There are important learnings from the important oral peptide delivery research conducted by Novo Nordisk. Their approach to creating oral semaglutide and oral insulin formulations was to consider two aspects in parallel. The first was to use medicinal chemistry to create long-acting potent stable peptides using modified and acylated amino acids to form moieties that could associate with human serum albumin in the case of semaglutide (for the protype injectable form) (Knudsen and Lau, 2019) and to protect against luminal peptidases in the case of the modified insulin, IO338 (Kjeldsen et al., 2021). These modifications were accompanied by studies showing that there was no reduction in receptor binding and efficacy for either peptide. The second parallel approach was to formulate the peptides with well-established permeation enhancers in solid dose formulations. The oral semaglutide formulation with SNAC made it to market, but the insulin one with $\mathrm{C}_{10}$ did not. The outcome from the discontinued oral insulin programme suggests that a commercially viable oral insulin formulation might still be possible if the oral bioavailability of a modified basal insulin could perhaps be increased to $\sim 10 \%$ in humans, as this would reduce the cost.

The Novo-Nordisk studies with semaglutide and SNAC offered convincing evidence that semaglutide absorption occurred from the stomach and that the main effect of SNAC was to buffer against pepsin, maintain semaglutide as a monomer, and act in a transcellular fashion on stomach parietal cells (Buckley et al., 2018). SNAC could not be substituted by other analogues from the Eligen ${ }^{\circledR}$ libraries, nor could semaglutide be substituted by liraglutide, thereby suggesting that the pairing of SNAC with semaglutide was unique. Yet, a 2011 scintigraphy study in humans demonstrated that another carrier from the Eligen ${ }^{\circledR}$ series of enhancers, monosodium N-(4-chlorosalicyloyl)4-aminobutyrate (5-CNAB), also enabled stomach absorption of insulin (Castelli et al., 2011), so there is much to address on how and where these type enhancers work and as to whether stomach absorption can also be exploited for orally-delivered insulin.

\section{The Promise From Ongoing Research in Oral Insulin Delivery}

With the exceptions of the atypical peptides, cyclosporin (Dunn et al., 2001) and voclosporin (Heo, 2021), the oral peptide delivery technologies developed to date based on permeation enhancers or nanotechnology do not appear to be capable of achieving $10 \%$ bioavailability for humans, no matter what the structure of the peptide is, be it stable or cyclic, or having low clearance. Perhaps this is a disservice to current efforts, as several recent studies in rodents suggest that substantial oral bioavailability for oral insulin (based indirectly on Area Above the Curve (AAC) calculations from plasma glucose reductions) can be achieved with high-performing new enhancer- and nanoparticle-based systems. Examples of enhancers include ionic liquids (Banerjee et al., 2018) and an strawberry-derived anthocyanidin, pelargonidin (Lamson et al., 2020a), while nanoparticles include anionic silica nanoparticles (Lamson et al., 2020b), and amphiphilic micelle nanocomplexes (Han et al., 2020). These 
examples for oral insulin delivery, albeit in rodents to date, appear to have surpassed previous efforts in terms of generating doubledigit oral bioavailability. Such technologies will require further data demonstrating robust parallel pharmacokinetics, reproducibility in other laboratories, and conversion to oral dosage forms that can be tested in large animal models.

In the past 5 years, there has been a spate of remarkable device designs inspired from transdermal delivery research that appear to out-perform permeation enhancers and nanotechnology. Rani Therapeutics (CA, United States) designed an enteric capsule that uses an internal balloon to actuate sucrose needles against the epithelia of the small intestine. A high relative oral bioavailability of $70 \%$ was reached for octreotide with the RaniPill ${ }^{\mathrm{TM}}$ (Dhalla et al., 2021), albeit with very large intra-subject variability. MIT researchers working with Novo Nordisk have created a device that actuated a millipost needle containing a dry powder of insulin in the stomach (Abramson et al., 2019a), as well as a capsule-released device that protrudes arms with microneedles in the small intestine (Abramson et al., 2019b). The SOMA stomach device of MIT/Novo Nordisk has recently been modified to accept liquid insulin in much higher concentrations and also to control needle retraction (Abramson et al., 2021). Insulin bioavailability of up to $80 \%$ has been achieved in pigs. Recent Start-Ups have created capsules activated by ultrasound (http://baywindbio.com/jetcap/) and ones where fluid actuates metal alloy hooks to achieve gastric adherence (www.biograil.com). New research also uses a microneedle system adapted to the oromucosal surface where insulin is delivered at high levels (Caffarel-Salvador et al., 2021). These promising first steps tested devices initially in pigs or dogs, therefore the final dosage form was created up-front and there was no need to spend years carrying out studies with miniaturised prototypes in rodents. Still, device technologies must address several fundamental questions concerning sufficient peptide loading, patient acceptance for very large capsules in some examples, potential intestinal blockage, inaccurate and inefficient needle actuation, as well as toxicological assessment of repeated epithelial perforation. In achieving a more than ten-fold increase in the oral delivery of peptides over other technologies, the gamut of device-based systems now emerging may be doing so by compromising important physiological parameters.

\section{Commercial Interest in the Oral Delivery of Insulin}

Examining the pipelines of biotech companies currently working on devices, few examples of insulin are now evident and most of the interest seems to be in accessing the large markets for GLP-1 RAs, dual glucose-dependent insulinotropic polypeptide (GIP) and GLP-1 RAs, anti-inflammatory biologics, antisense oligonucleotides, and mRNA. There are several reasons why oral delivery of insulin may no longer be considered by Biotech as a commercial option. Perhaps there is some reticence at pursuing prandial insulin given the speed of insulin delivery required ahead of a meal and the likelihood of interactions with food? Maybe the low therapeutic index and high costs have reduced commercial interest? Furthermore, bioavailability might not be the right criterion for successful delivery of insulin, given that up to $50 \%$ of insulin will be metabolised in the liver target following intestinal delivery (Taverner et al., 2015). If sequestration of insulin by the liver can be achieved from an oral system, then the accompanying plasma insulin levels should ideally be low. Perhaps that is just an excuse for achieving low bioavailability with sub-optimal formulations ! To address this possibility, pharmacokinetic metrics should be combined with measures of the plasma biomarker, glycosylated haemoglobin (HBA1c), so that pharmacokinetics and pharmacodynamics can be related. If Type 2 patients cannot be converted to an all-oral insulin regimen, will this patient cohort really welcome an oral basal insulin while still having to continuing with prandial injections (or inhalations), or vice-versa? Are Type 1 diabetic patients, who are fully dependent on insulin, a better potential target group for oral administration of insulin, or are the efforts to make an integrated closed-loop insulin pump going to make that question moot?

\section{CONCLUSION}

As we pass one hundred years since the discovery of insulin, will we make tangible progress towards an oral insulin product for diabetic patients? Some have suggested that it is an unattainable goal indicative of scientific hubris (Florence, 2015). On the contrary, an article entirely supportive of the rationale for an oral insulin product has just been published by Pinelo et al. (2021). From the forgoing, the development of an oral insulin product encompasses many aspects ranging from the technical challenges to achieve sufficient absorption, safety issues, which type of insulin to pursue (basal or mealtime), patient preferences, and costs and reimbursement questions. For now, in the absence of piquing the interest of Pharma to go back to the well once more, insulin's main role seems to be as a proof-of-principle benchmark for oral macromolecule delivery technologies.

\section{AUTHOR CONTRIBUTIONS}

DB wrote the complete manuscript.

\section{FUNDING}

This publication was supported in part by a grant from Science Foundation Ireland (SFI) and the European Regional Development Fund (ERDF) under grant number 13/RC/ 2073_2, the SFI CURAM Centre for Medical Devices. 


\section{REFERENCES}

Abramson, A., Caffarel-Salvador, E., Khang, M., Dellal, D., Silverstein, D., Gao, Y., et al. (2019a). An Ingestible Self-Orienting System for Oral Delivery of Macromolecules. Science 363 (6427), 611-615. doi:10.1126/science.aau2277

Abramson, A., Caffarel-Salvador, E., Soares, V., Minahan, D., Tian, R. Y., Lu, X., et al. (2019b). Luminal Unfolding Microneedle Injector for Oral Delivery of Macromolecules. Nat. Med. 25 (10), 1512-1518. doi:10.1038/s41591-019-0598-9

Abramson, A., Frederiksen, M. R., Vegge, A., Jensen, B., Poulsen, M., Mouridsen, B., et al. (2021). Oral delivery of Systemic Monoclonal Antibodies, Peptides and Small Molecules using Gastric Auto-Injectors. Nat. Biotechnol. doi:10.1038/ s41587-021-01024-0

Al-Tabakha, M. M. (2015). Future prospect of Insulin Inhalation for Diabetic Patients: The Case of Afrezza versus Exubera. J. Controlled Release 215, 25-38. doi:10.1016/j.jconrel.2015.07.025

Anderson, S. L., Beutel, T. R., and Trujillo, J. M. (2020). Oral Semaglutide in Type 2 Diabetes. J. Diabetes its Complications 34 (4), 107520. doi:10.1016/ j.jdiacomp.2019.107520

Banerjee, A., Ibsen, K., Brown, T., Chen, R., Agatemor, C., and Mitragotri, S. (2018). Ionic Liquids for Oral Insulin Delivery. Proc. Natl. Acad. Sci. USA 115 (28), 7296-7301. doi:10.1073/pnas.1722338115

Brayden, D. J., Hill, T. A., Fairlie, D. P., Maher, S., and Mrsny, R. J. (2020). Systemic Delivery of Peptides by the Oral Route: Formulation and Medicinal Chemistry Approaches. Adv. Drug Deliv. Rev. 157, 2-36. doi:10.1016/j.addr.2020.05.007

Brayden, D. J., and Maher, S. (2021). Transient Permeation Enhancer ${ }^{\circledR}\left(\mathrm{TPE}^{\circledR}\right)$ Technology for Oral Delivery of Octreotide: a Technological Evaluation. Exp. Opin. Drug Deliv. 28, 1-11. Available at: https://www.tandfonline.com/doi/full/ 10.1080/17425247.2021.1942838 (Published online Jun 28, 2021).

Buckley, S. T., Bækdal, T. A., Vegge, A., Maarbjerg, S. J., Pyke, C., Ahnfelt-Rønne, J., et al. (2018). Transcellular Stomach Absorption of a Derivatized Glucagon-like Peptide-1 Receptor Agonist. Sci. Transl. Med. 10 (467), eaar7047. doi:10.1126/ scitranslmed.aar7047

Caffarel-Salvador, E., Kim, S., Soares, V., Tian, R. Y., Stern, S. R., Minahan, D., et al. (2021). A Microneedle Platform for Buccal Macromolecule Delivery. Sci. Adv. 7 (4), eabe2620. doi:10.1126/sciadv.abe2620

Castelli, M. C., Connor, A., Wilding, I., and Riley, M. G. (2011). A Gamma Scintigraphic Clinical Study of the Absorption of Insulin Co-formulated with Eligen ${ }^{\circledR}$ Absorption Enhancer, 4-CNAB. FASEB J. 25 (Suppl. 1), lb394. (Abstract). doi:10.1096/fasebj.25.1_supplement.lb394

Damgé, C., Michel, C., Aprahamian, M., and Couvreur, P. (1988). New Approach for Oral Administration of Insulin with Polyalkylcyanoacrylate Nanocapsules as Drug Carrier. Diabetes 37 (2), 246-251. doi:10.2337/diab.37.2.246

Dapergolas, G., and Gregoriadis, G. (1976). Hypoglycqmic Effect of LiposomeEntrapped Insulin Administered Intragastrically into Rats. The Lancet 308 (7990), 824-827. doi:10.1016/s0140-6736(76)91209-5

Dhalla, A. K., Al-Shamsie, Z., Beraki, S., Dasari, A., Fung, L. C., Fusaro, L., et al. (2021). A Robotic Pill for Oral Delivery of Biotherapeutics: Safety, Tolerability, and Performance in Healthy Subjects. Drug Deliv. Transl. Res. 19. doi:10.1007/s13346-021-00938-1

Drucker, D. J. (2020). Advances in Oral Peptide Therapeutics. Nat. Rev. Drug Discov. 19 (4), 277-289. doi:10.1038/s41573-019-0053-0

Dunn, C. J., Wagstaff, A. J., Perry, C. M., Plosker, G. L., and Goa, K. L. (2001). Cyclosporin. Drugs 61 (13), 1957-2016. doi:10.2165/00003495-200161130-00006

Eldor, R., Arbit, E., Corcos, A., and Kidron, M. (2013). Glucose-reducing Effect of the ORMD-0801 Oral Insulin Preparation in Patients with Uncontrolled Type 1 Diabetes: a Pilot Study. PLoS One 8 (4), e59524. doi:10.1371/journal.pone.0059524

Florence, A. T. (2015). Oral Insulin Delivery: a Chimera? Int. J. Pharmaceutics 495, 218-219. doi:10.1016/j.ijpharm.2015.08.092

Gentile, S., Strollo, F., Strollo, F., and Ceriello, A. (2016). AMD-OSDI Injection Technique Study GroupLipodystrophy in Insulin-Treated Subjects and Other Injection-Site Skin Reactions: Are We Sure Everything Is clear? Diabetes Ther. 7 (3), 401-409. doi:10.1007/s13300-016-0187-6

Halberg, I. B., Lyby, K., Wassermann, K., Heise, T., Zijlstra, E., and PlumMörschel, L. (2019). Efficacy and Safety of Oral Basal Insulin versus Subcutaneous Insulin Glargine in Type 2 Diabetes: a Randomised, Double-Blind, Phase 2 Trial. Lancet Diabetes Endocrinol. 7 (3), 179-188. doi:10.1016/S2213-8587(18)30372-3
Han, X., Lu, Y., Xie, J., Zhang, E., Zhu, H., Du, H., et al. (2020). Zwitterionic Micelles Efficiently Deliver Oral Insulin without Opening Tight Junctions. Nat. Nanotechnol. 15 (7), 605-614. doi:10.1038/s41565-0200693-6

Harrison, G. A. (1923). Insulin in Alcoholic Solution by the Mouth. Bmj 2, 1204-1205. doi:10.1136/bmj.2.3286.1204

Heo, Y.-A. (2021). Voclosporin: First Approval. Drugs 81 (5), 605-610. doi:10.1007/s40265-021-01488-z

Igarashi, A., Hansen, B. B., Langer, J., Tavella, F., Collings, H., Davies, N., et al. (2021). Preference for Oral and Injectable GLP-1 RA Therapy Profiles in Japanese Patients with Type 2 Diabetes: A Discrete Choice Experiment. Adv. Ther. 38 (1), 721-738. doi:10.1007/s12325-020-01561-1

Kjeldsen, T. B., Hubálek, F., Tagmose, T. M., Pridal, L., Refsgaard, H. H. F., Porsgaard, T., et al. (2021). Engineering of Orally Available, Ultralong-Acting Insulin Analogues: Discovery of OI338 and OI320. J. Med. Chem. 64 (1), 616-628. doi:10.1021/acs.jmedchem.0c01576

Knox, R. (2020). Insulin Insulated: Barriers to Competition and Affordability in the United States Insulin Market. J. L. Biosciences 7, 1-25. doi:10.1093/ jlb/lsaa061

Knudsen, L. B., and Lau, J. (2019). The Discovery and Development of Liraglutide and Semaglutide. Front. Endocrinol. 10, 155. doi:10.3389/ fendo.2019.00155

Lamont, T., Cousins, D., Hillson, R., Bischler, A., and Terblanche, M. (2010). Safer Administration of Insulin: Summary of a Safety Report from the National Patient Safety Agency. Br. Med. J. 341. doi:10.1136/bmj.c5269

Lamson, N. G., Fein, K. C., Gleeson, J. P., Xian, S., Newby, A., Chaudhary, N., et al. (2020a). From Farm to Pharmacy: Strawberry-Enabled Oral Delivery of Protein Drugs. BioRxiv preprint. doi:10.1101/2020.03.11.987461

Lamson, N. G., Berger, A., Fein, K. C., and Whitehead, K. A. (2020b). Anionic Nanoparticles Enable the Oral Delivery of Proteins by Enhancing Intestinal Permeability. Nat. Biomed. Eng. 4 (1), 84-96. doi:10.1038/ s41551-019-0465-5

Mathieu, C. (2019). Oral Insulin: Time to Rewrite the Textbooks. Lancet Diabetes Endocrinol. 7 (3), 162-163. doi:10.1016/S2213-8587(19)30005-1

Mathiowitz, E., Jacob, J. S., Jong, Y. S., Carino, G. P., Chickering, D. E., Chaturvedi, P., et al. (1997). Biologically Erodable Microspheres as Potential Oral Drug Delivery Systems. Nature 386 (6623), 410-414. doi:10.1038/386410a0

McCall, A. L. (2012). Insulin Therapy and Hypoglycemia. Endocrinol. Metab. Clin. North America 41 (1), 57-87. doi:10.1016/j.ecl.2012.03.001

McGill, J. B., Peters, A., Buse, J. B., Steiner, S., Tran, T., Pompilio, F. M., et al. (2020). Comprehensive Pulmonary Safety Review of Inhaled Technosphere Insulin in Patients with Diabetes Mellitus. Clin. Drug Investig. 40 (10), 973-983. doi:10.1007/s40261-020-00958-8

Melmed, S., Popovic, V., Bidlingmaier, M., Mercado, M., van der Lely, A. J., Biermasz, N., et al. (2015). Safety and Efficacy of Oral Octreotide in Acromegaly: Results of a Multicenter Phase III Trial. J. Clin. Endocrino.l Metab. 100 (4), 1699-1708. doi:10.1210/jc.2014-4113

Morishita, M., Goto, T., Peppas, N. A., Joseph, J. I., Torjman, M. C., Munsick, C. et al. (2004). Mucosal Insulin Delivery Systems Based on Complexation Polymer Hydrogels: Effect of Particle Size on Insulin Enteral Absorption. J. Controlled Release 97 (1), 115-124. doi:10.1016/j.jconrel.2004.03.008

Pinelo, R., Roque, L., and Pinto-Reis, C. (2021). Oral Insulin Delivery: utopia, Currently Possible or a Near Reality? Ther. Deliv. 12 (6), 477-488. doi:10.4155/ tde-2021-0021

Pridgen, E. M., Alexis, F., Kuo, T. T., Levy-Nissenbaum, E., Karnik, R., Blumberg, R. S., et al. (20132013). Transepithelial Transport of Fc-Targeted Nanoparticles by the Neonatal Fc Receptor for Oral Delivery. Sci. Translational Med. 5 (213), 213ra167. doi:10.1126/scitranslmed.3007049

Rubin, R. R., Peyrot, M., Kruger, D. F., and Travis, L. B. (2009). Barriers to Insulin Injection Therapy. Diabetes Educ. 35 (6), 1014-1022. doi:10.1177/0145721709345773

Saffran, M., Field, J. B., Peña, J., Jones, R. H., and Okuda, Y. (1991). Oral Insulin in Diabetic Dogs. J. Endocrinol. 131 (2), 267. doi:10.1677/joe.0.13102610.1677/ joe. 0.1310267

Saffran, M., Pansky, B., Budd, G. C., and Williams, F. E. (1997). Insulin and the Gastrointestinal Tract. J. Controlled Release 46, 89-98. doi:10.1016/s01683659(96)01578-7

Samson, S. L., Nachtigall, L. B., Fleseriu, M., Gordon, M. B., Bolanowski, M., Labadzhyan, A., et al. (2020). Maintenance of Acromegaly Control in 
Patients Switching from Injectable Somatostatin Receptor Ligands to Oral Octreotide. J. Clin. Endocrinol. Metab. 105 (10), e3785-e3797. doi:10.1210/ clinem/dgaa526

Sharma, S. K., Kant, R., Kalra, S., and Bishnoi, R. (2020). Prevalence of Primary Nonadherence with Insulin and Barriers to Insulin Initiation in Patients with Type 2 Diabetes Mellitus - an Exploratory Study in a Tertiary Care Teaching Public Hospital. Eur. Endocrinol. 16 (2), 143-147. doi:10.17925/EE.2020.16.2.143

Taverner, A., Dondi, R., Almansour, K., Laurent, F., Owens, S.-E., Eggleston, I. M., et al. (2015). Enhanced Paracellular Transport of Insulin Can Be Achieved via Transient Induction of Myosin Light Chain Phosphorylation. J. Controlled Release 210, 189-197. doi:10.1016/j.jconrel.2015.05.270

Vecchio, I., Tornali, C., Bragazzi, N. L., and Martini, M. (2018). The Discovery of Insulin: an Important Milestone in the History of Medicine. Front. Endocrinol. 9 (9), 613. doi:10.3389/fendo.2018.00613

Zijlstra, E., Heinemann, L., and Plum-Mörschel, L. (2014). Oral Insulin Reloaded. J. Diabetes Sci. Technol. 8 (3), 458-465. doi:10.1177/1932296814529988
Conflict of Interest: DB consults for Pharma companies working on oral peptide delivery and has active grants on the topic from Science Foundation Ireland, Enterprise Ireland, and Gattefosse SAS, France.

Publisher's Note: All claims expressed in this article are solely those of the authors and do not necessarily represent those of their affiliated organizations, or those of the publisher, the editors and the reviewers. Any product that may be evaluated in this article, or claim that may be made by its manufacturer, is not guaranteed or endorsed by the publisher.

Copyright $\odot 2021$ Brayden. This is an open-access article distributed under the terms of the Creative Commons Attribution License (CC BY). The use, distribution or reproduction in other forums is permitted, provided the original author(s) and the copyright owner(s) are credited and that the original publication in this journal is cited, in accordance with accepted academic practice. No use, distribution or reproduction is permitted which does not comply with these terms. 